\title{
Media in COVID-19: A Double Edge Sword.
}

\author{
Snehal Gondhalekar \\ Intern, Dept. of Community Medicine, Jawaharlal Nehru Medical College, Datta Meghe Institute of Medical \\ Sciences (Deemed to be University), Sawangi (Meghe), Wardha-442001, Maharashtra, \\ Email-gondhalekar97@gmail.com \\ Review Article \\ Conflict of Interest: None
}

\begin{abstract}
:
This research aims to show the impression of Media on COVID-19 amongst common public. This research focuses on the relationship and its influence globally on the people in every domain of their life and its effects on their health.As we all know, While at same time as we are witnessing a worldwide health danger named COVID-19 since the previous few months the unfold of records approximately as compared to the pandemic has been an awfully travelled lot faster than the virus itself. Hence its miles challenging to find a pleasant stability among the toxic overuse of media era and healthful harnessing of healthcare records.As same as we have seen with different emergencies, individuals everywhere on the world contact each other through web-based media to sort out what's going on.

We break down commitment and interest in the COVID-19 point and give a differential appraisal on the development of the talk on a worldwide scale for every stage and their clients. We fit data spreading with pestilence models describing the essential multiplication number for every web-based media stage. Additionally, we distinguish data spreading from flawed sources, finding various volumes of falsehood in every stage. Be that as it may, data from both dependable and faulty sources don't present diverse spreading designs. At last, we give stage subordinate mathematical appraisals of bits of gossip intensification.Capable utilization of these instruments can help rapidly spread significant new data, important new logical discoveries, share analytic, treatment, and follow up conventions, just as analyse various methodologies all around the world, eliminating geographic limits without precedent for history.
\end{abstract}

Keywords :COVID-19, Social media, Misinformation, Health, Awareness, information dissemination, effects, roles, platforms.

\section{INTRODUCTION}

Aswe were eyewitness to the global fitness danger named COVID-19 considering the fact that previous couple months, the unfold of statistics about the pandemic has been a lot quicker than virus itself. COVID-19 also called as Novel coronavirus. Such a big threat can be made aware to public quickly by use of media and social media, which is a PC based innovation that encourages data by working of virtual organization and network. It is web based and gives us fast electronic correspondence of substance. A big positive effect of social media is that it is easier to spread an information within a short time. It has got tremendous media effect which can be intentional or unintentional on the part of both the one that sends as well as the one that receives. The effects it may cause amongst individual can be of cognitive, belief, affective, attitudinal, physiological and behavioural. The media can influence public in different modalities like by acquiring, triggering, altering or reinforcing.

Inside couple of long stretches of the compliance of the COVID-19 in China, deluding gossipy tidbits and paranoid ideas about its starting point was coursed matched with dread causing extraordinary trouble among public. Hence not exclusively did the infection spread quickly, yet so did its data and deception about the flare-up and in this way the frenzy was made among people in general.Media played an important role 
during this time. The different type of media through which information can be spread are namely-

- Print media (newspapers)

- Broadcast media (televisions)

- Internet

- Social media, which are most trending nowadays

- There are different types of social media like

- Person to person communication destinations (Facebook, Twitter),

- Social audit locales, Image sharing locales (Instagram, and Snapchat),

- Video facilitating locales (YouTube),

- Community websites (Medium and Tumblr),

- Discussion destinations (Reddit and Quora) and so on.Example: MEMES

\section{CORONOVIRUS}

In December 2019 there were increased cases with people having cluster of pneumonia in china. Later on it was discovered it was due to previously known virus as coronavirus, which is a member of the family coronaviridae.It is a large group of virus having envelope, genetic material, protein spikes. Since it looks like crown hence was named as corona by JUNE ALMEIDA and DAVID TYRRELL.There existence vary in different types like gastrointestinal which is usually mild type or respiratory type like common cold or pneumonia but can end up causing severe disease manifestations like those in past.

SARS - CoV China 2003

MERS - CoV SaudiArabia 2012

2019n - CoV China 2019

\section{THE 2019 NOVEL CORONAVIRUS}

The 2019 Novel coronavirus was first found in the city Wuhan in China near seafood and animal market area where it affected people and the disease transmitted to other family members and health care workers from the individuals suffering from it. It is a respiratory water droplet transmitted disease. Its origin is said to be among various range of animals. The sickness principally influences the respiratory framework with manifestations going from fever, mild shortness of breaths, to extreme desaturation, causing respiratory disappointment. In spite of the lung harm as grown-up respiratory trouble disorder (ARDS), there are reports of the novel infection making a thromboembolic condition in the body and henceforth causing MI and pulmonary embolism. It can likewise bring about kidney derangements in a few patients. Methods of spread reach from droplets, airborne, or feco-oral to contact spread. There is information on infections remaining sustained on surfaces from a couple of hours to numerous days. This heterogeneous range of infection is unsettling and one reason for the expanded casualty of the illness.

\section{ROLE OF SOCIAL MEDIA:}

It is a major source of information as the spread of sickness and the resultant human practices can be impacted by stream and vectors of data. (1)It has ability to capture a greater influence on public response to the covid-19 outbreak.It serves as a good media for marketing brands and products.It is a powerful way to bring calmness and positivity amongst people in such a panic condition.No platform is perfect but ability to share experience with family and friends helps to fight isolation of both types literal as well as emotional hence establishing a mutual empathic feeling with each other that we all are in this together.It is the quickest method to share lifesaving vital knowledge amongst everyone including the professionals at global level.It is the most popular and effective way to spread awareness to recognize and seek medical attention as early as possible if needed so that further complications can be avoided. It helps to break the chain transmission in order to weaken and almost win the fight against the disease. 
It layouts the hazards of falsehood marvels during the administration of infection outbreaks since it could even accelerate the scourge cycle by impacting and dividing social response. For instance, news has as of late foreseen gossip about the conceivable lock-down of a particular area to forestall pandemics, distributing the news hours before the authority correspondence from the person in charge of the state. Thus, individuals stuffed trains and air terminals to escape from that place toward various locales before the lock-down was set up, disturbing the public authority activity planned to contain the pandemic and conceivably expanding disease (2). Consequently, a significant examination challenge is to decide how individuals look for or evade data and how those choices influence their behaviour, especially when the consistent pattern of media reporting-overwhelmed by the disintermediated dispersion of dataadjusts the manner in which data is devoured and covered.

\section{DISCUSSION: \\ WHY IS MEDIA A DOUBLE EDGE SWORD}

Even though media is a one of the best platform still it can influence people in both negative and positive ways like a double edge sword. As it is a platform of spreading information, free expression and feedback is rapid, there are chances of spreading misleading information too. Therefore its affects can be categorized under Positive and Negative influence.

These viewpoints make a public concern and power the overall population to look for help from the most open ways accessible to them. For a great many people, it's either the web or media, which incorporates print, just as communicated choices. The web is considered an overall media. In a scourge or pandemic, controlling the spread of infection is a fundamental necessity. It requires early acknowledgment of symptomatology, brief analytic measures, successful home and hospice the executives, and suitable preventive advances. This thusly, requires the part of changing offices going from government to medical care, to the media, to the overall population itself. At whatever point another infection or bacterial sickness arises, it experiences confined transmission, intensification in the spread, lastly, the abatement with effective measures. The controlling measures are made at each stride of the chain. They incorporate expectation about the probable broad disease, early discovery, powerful regulation, control and moderation measures, and in conclusion, destruction. As indicated by WHO, it includes the coordination of responders, appropriate wellbeing data framework, and overseeing correspondence chances (3). Media assumes an essential part at each progression. The strategy for news detailing changes the conduct of individuals and their perspectives.

On the one hand, it helped people to adopt essential protective measures. On the other hand, some people started stigmatizing diseased persons from inappropriate articles published in some newspapers. This is an example that indicates that the interaction between media awareness and disease control is a two-directional approach.

\section{NEGATIVE INFLUENCE}

- Advanced screen time has expanded as individuals are remaining at home. Individuals are regularly observed with their eyes stayed with cements to their TV, PCs or portable screens, occupied in devouring the news channels, this makes a need among the public remain refreshed about each feature of the pandemic. This additionally expands the mental uneasiness and actual agitation.

- Negative translation of the ailment by the majority can prompt possible admixture of phony data, with the 
significant test being coaxing out reality, thusly wellbeing related deception turns out to be more vital during a pandemic like Coronavirus when the dread of an obscure contamination without a complete fix blends in with an on edge mind that will in general effectively acknowledge quick arrangements and hypotheses, regardless of their coherent thinking.

- One wrong message sent, in some unacceptable hands, can cause the far and wide deception as it moves along in chains. (4)

- Many trouble calls that we hear to these days are identified with impulsive utilization of the web and web-based media prompting mental wellbeing related issues like tension, physical grumblings, nervousness, burdensome issues, fomentation and a sleeping disorder.

- In kids and youths it can cause gaming dependence as they are presented to more online innovation.

- Web-based media-related fault can likewise prompt shame, underestimation, communalism and viciousness, particularly at such at such critical times.

- The effect of media detailing total lockdown and public slants may affect the general population and private areas in settling on choices on stopping certain administrations including carrier administrations, unbalanced to the genuine general wellbeing need. Travel limitations are one model, and we need to unload the impact of webbased media on such estimates that conveying an enormous monetary misfortune (5).

- These platforms go about as facilitators and multipliers of Coronavirus related falsehood. This trade-offs flare-up reaction and expands public disarray about who and what data sources to be believed; it creates dread and frenzy because of unsubstantiated gossipy tidbits and misrepresented cases about a data.

- In China, tattle spread that bioweapons research in a Wuhan lab achieved the genetic planning of Coronavirus that was then conveyed. Such gossipy goodies may have even imperiled the working association between Western scientists and their Chinese accomplices searching for a Coronavirus vaccination (6).

- HCQ under limelight - Media is the essential root of data and assumes a fundamental job in teaching the majority. Nonetheless, when excessively energetic sources spread data without appropriate confirmation, not exclusively would it be able to be hurtful however it can have unintended results. The hydroxychloroquine (HCQ) (7) model fits the situation. HCQ, a lyso-somatotrophic specialist, is an endorsed medication to treat sickness caused by malaria and some immune system infections. Its ability to battle certain infections is clarified by its job in hindering the capacity of lysosomes. It is proposed that at an acidic $\mathrm{pH}$, certain infections, passes through the plasma membranes of cells, intertwine with lysosomal layers, along these lines entering the cells and duplicating. Chloroquine being a feeble base, goes into lysosomes and raises the $\mathrm{pH}$ of the lysosome. As the $\mathrm{pH}$ rises, lysosomal proteins neglect to work, and infections requiring acidic $\mathrm{pH}$ cannot enter the cells. The positive part of chloroquine against SARSCoV-2 has been shown in vitro. The adequacy of HCQ in normal people is yet to be resolved. A few deaths were accounted for from chloroquine abuse.

This inaccurate slip-up demonstrated dangerous for the general population. Hydroxychloroquine is reasonable, effectively accessible in malarial endemic areas, and turned out to be profoundly pursued after its exposure on a few media 
stages. It vanished from the market like a phantom, costs soar, and merchants fired loading up on it. This made an inventory network shortfall and its deficiency left a significant effect on individuals utilizing it as an administration for their immune system infections. Medical services suppliers noted expanded number of lupus infection flare ups and a spike in rheumatoid joint inflammation cases.

\section{POSITIVE INFLUENCE}

- In a quickly spreading pandemic like this, all things considered, an absence of mindfulness and readiness put medical care personals in danger. Subsequently, conveying fast, solid data that tends to basic disease control issues (8) like tracheal intubation is known to be related with a high danger of transmission of viral diseases to medical services workers, hence it is of key importance. (9)

- Well-designed free open access instructive material ought to distil key data in a reasonable, noteworthy arrangement, while matched with webbased media-controlled scattering utilizing informal organizations, notwithstanding conventional specialized techniques. Using webbased media in this manner has indicated guarantee as a speedier other option. The utilization of the standards of the Free Open Access Medical Education (FOAM) networks (10) further give genuine instances of the adequacy of making data uninhibitedly accessible.

- Many influencer and celebrity postings have centred around \#StayHome and \#StayHealthy themes.

- The linkage of different media stages with logical information bases like Pubmed, Google Scholar, and so forth, can give suitable inquiry direction (11)

- Campaigns such as \#See10Do10 can make an occasionally decent method of imparting socially valuable. Screen time is depended upon to increase among adults similarly as children during the Coronavirus pandemic so \#See10Do10 is just a single outline of the way in which requests spread immediately, even in the midst of a pandemic, and it has all the earmarks of being both obvious and essential for such a virality to be handled towards productive measures to keep ourselves sound at home while the spread of contamination (12).

- COVID-19 patient shares her experience on Facebook

Amidst the Covid alert over the world, a woman from the US who was sullied with Covid during the latest multi day stretch of February, post on Facebook about her involvement concerning Coronavirus 19. In the post, the Seattle-based woman named Elizabeth Schneider revealed how she gotten the disease, signs, resistant system, security measures and misinterpretations about it and the way that she has now recuperated.

Her post has turned into a web sensation and has more than 27,000 offers and 3,500 remarks.

"I trust this data assists somebody with trying not to become ill and additionally push to get tried in the near future so you know to segregate before it deteriorates or to get clinical consideration on the off chance that you have respiratory pain," she composed. "You probably won't pass on, however would you like to hazard spreading it to a friend or family member more than 60 or somebody with an invulnerability issue? Remain solid people!" she closed. Subsequently it contacted numerous individuals and gave them would like to battle against it together by getting intellectually solid from the experience stories shared like hers. (13).

Simple techniques like 8 steps of handwashing, social distancing, use of mask and sanitizers etc, when shared in a proper way can help to combat the virus at 
community level until a definitive treatment is approved for cure. As they saying goes prevention is better than cure.

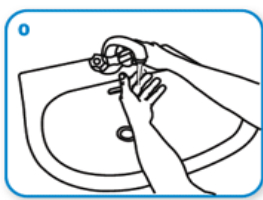

Wet hands with water

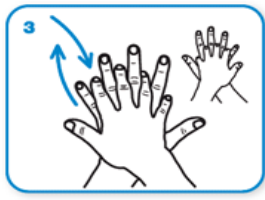

right palm over left dorsum with interlaced fingers and vice versa

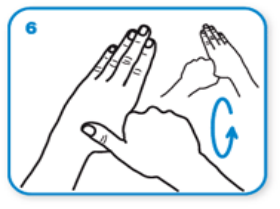

rotational rubbing of left thumb clasped in right palm and vice versa

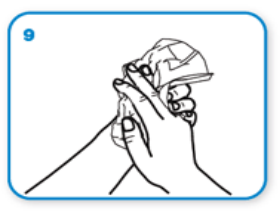

dry thoroughly with a single

- Youtube, anthems like mask nahi toh tokenge, corona ko rokenge ; facebook more together Pooja didi ; corona break the chain advertisement etc contribute to widespread the information to public.

- Whatsapp : those people who are home quarantined cannot go outside to buy vegetables and fruits, medicines etc but WhatsApp have connected people to one another through it, people send grocery list, vegetable list etc on WhatsApp to the shop and get the products home delivered at there door and pay them through paytm or gpay etc hence this avoids contact of the delivery guy with the patient, ensures patient receives food and medicines timely and patient does not have to go out avoiding chained or mass spread of the virus in community. WhatsApp also helped family members connected to each other see each other and be in

\section{Step of handwashing}

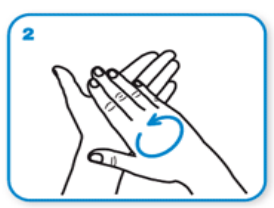

Rub hands palm to palm

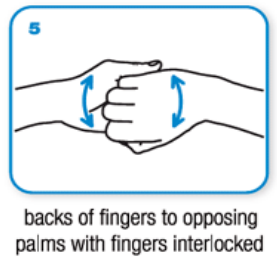

palms with fingers interlocked

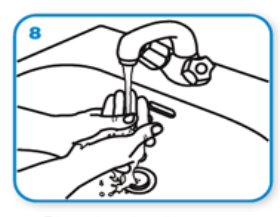

Rinse hands with water

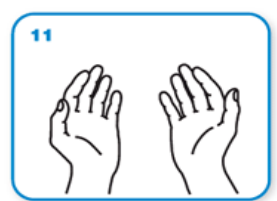

...and your hands are safe.

contact with each other even after being quarantined in different rooms with the help of one of its feature like WhatsApp call which enabled family members to support each other and stay stronger together.

The effect that data or deception can have on human conduct is amazing. It can go from flawed medicines and resistance to freeze, widespread panic and rivalry for medical services assets to important and ideal data appeared to improve readiness for irresistible sicknesses and fortify general wellbeing framework at each level (14).

Keeping up a cognizant and educated good ways from online media can help increment the Coronavirus extra time, which is so essential for mental prosperity. Innovation can be utilized for social connectedness instead of separating us in our own advanced spaces. What we all 
would need most is to forestall Coronavirus from attacking our psychological harmony. In this way, allowed us to attempt to rehearse digital distancing. As the saying goes, "Discipline is choosing between what you want now and what you want most."

Pandemics will require co-ordinated overall response procedures. Progressed associations and online media stages can and should be at the centre of these methodology, since their responses and energy to cooperate with governments and general prosperity specialists will choose if electronic media is viewed as a favourable or hypochondriac vector of pandemic response .

On the off chance that we could cause \#See10Do10 to implement responsibility-10 different ways to remain inside or keep six-foot distances at the supermarket, 10 different ways to help medical services labourers take care of their responsibilities, 10 different ways to deal with old neighbours from a remote place, 10 different ways to forestall Covid from entering your own home-at that point possibly we could utilize the time we as of now spend gazing at the screen, and show proactive kindness each post in turn. Nonetheless, paying little attention to how much false data has been passed across, one should not neglect to understand the surprising focal points which online media has accommodated the public of every country. This is rather than different pandemics, for example, the Influenza of 1918 when online media was not in presence and it was essentially troublesome, particularly for the less special with no entrance, to stay aware of the news (14). In any case, lately, online media stages are immediate and effective in staying aware of discoursed encompassing the pandemic and this isn't confined to one place alone (15). Through the equivalent media, data is redressed and checked by the correct sources. It consequently gets fundamental to effectively expose counterfeit news and to edify individuals and they should be wise in sending mysterious news and in devouring each data they get from the web as an outline for their responses(16-20). Besides, we suggest making a model to assess the media reaction toward the finish of every pandemic. This assessment can fill in as a criticism for the media to help devise better and more successful techniques to control and forestall resulting flare-ups.

\section{CONCLUSION:}

We can conclude that with legitimate equilibrium we can define limits at singular level to utilize media with a feeling of obligation and clearness to decide to trust on media with rationale and thinking.

\section{ACKNOWLEDGEMENT}

Would like to acknowledge this to my family and friends for helping me out always with their support, and expertise.

\section{FUNDING INFORMATION}

Not applicable.

Declaration of conflicting interest

The creators announce that they have no known battling money related interests or individual associations that may have appeared to affect the work uncovered in this paper.

\section{REFERENCES:}

[1] Valck Kristine De. What is the role of social media during the COVID19crises.hec paris. 2020 Apr17

[2] Hussain W .Role of social media in COVID-19 Pandemic. The international journal of frontiersciences. 2020 Apr 19;4

[3] AR Ahmad, HR Murad. The impact of social media panic during the COVID-19pandemic. J Jedinternet. 2020 May 19 
[4] Ians . COVID-19 : Social media playing important role to keep people motivated. 2020 May8

[5] Awasthi Prashasti. Heres what social media apps are doing to fight COVID-19. 2020 Apr 23

[6] Gilsenan Katie. Closely connected: Social Media's role COVID-19. 2020 Jul1

[7] Jamal Alfea. How teens are using social media, technologies to support each other amid social distancing. Washington DC. Assian news international. 2020 Jun 24

[8] Das Ronnie ,Ahmed Wasim.Despite concerns COVID-19 shows how social media demons become an essential tool in the democratisation of knowledge. 2020 Jun 5.

[9] Kushner Jakson. The role of social media during pandemic. 2020 Mar 25

[10] M Cinelli W Quattrociocehi A Galeazzi. THE COVID 19 Social media infodemic ScientificReport2020 Oct 6;10

[11] A Anwar MMalik V raees. Role of mass media and public health communications in the COVID-19 pandemic. 2020 Sep 14

[12] Obi-AniA Ngozika Anikwenze Chinenye and Isiani Mathias Chukwudi. Social media and COVID 19 pandemic: Observation from Nigeria .2020 JULY 29

[13] Q Tang K Zhang Y Li. The important role of social media during the COVID 19epidemic . Disaster medicine and public health preparedness. 2020 Sep 1

[14] Saud Mahammad musta Ida Masud Rachman. Usage of social media during the pandemic seeking support and awareness about COVID 19through social media platform. Journal of Public Affairs an International Journal. 2020 Sep 15

[15] Depoux Anneliese Martin Sam Karafillactus Emilie Preet Raman
Smith Annelies Wilder Larson Heidi .The pandemic of social media travels faster than the COVID 19 outbreak. Journal of Travel Medicine 32020 Apr 3;27.

[16] Srivastava, K.C., D. Shrivastava, K.G. Chhabra, W. Naqvi, and A. Sahu. "Facade of Media and Social Media during Covid-19: A Review." International Journal of Research in Pharmaceutical Sciences 11, no. Special Issue 1 (2020): 142-49. https://doi.org/10.26452/ijrps.v11iSP L1.2288.

[17] Bakshi, S., V. Toshniwal, A. Agrawal, S. Acharya, and S. Shukla. "Awareness and Psychosocial Effects of Covid-19 Pandemic on Health Care Professionals and Medical Students across the State of Maharashtra." International Journal of Current Research and Review 12, no. 22 Special Issue (2020): S-122-S125.

https://doi.org/10.31782/IJCRR.2020 .SP74.

[18] Kaple, M.N., C. Mahakalkar, M. Philip, and S. Kshirsagar. "COVID 19 Pandemic: Social Aspects and Safe Behaviours." Journal of Critical Reviews 7, no. 8 (2020): 1066-69. https://doi.org/10.31838/jcr.07.08.22 2.

[19] Toshida, T., and C. Jagruti. "COVID-19 - Rumours and Facts in Media." International Journal of Research in Pharmaceutical Sciences 11, no. Special Issue 1 (2020): 17174.

https://doi.org/10.26452/ijrps.v11iSP L1.2344.

[20] Gaidhane, A., A. Sinha, M. Khatib, P. Simkhada, P. Behere, D. Saxena, B. Unnikrishnan, M. Khatib, M. Ahmed, and Q.S. Zahiruddin. "A Systematic Review on Effect of Electronic Media on Diet, Exercise, and Sexual Activity among Adolescents." Indian Journal of 
PSYCHOLOGY AND EDUCATION (2021) 58(2): 730-738

An Interdisciplinary Journal

Article Received: 16th October, 2020; Article Revised: 30th December, 2020; Article Accepted: 08th January, 2021

Community Medicine 43, no. 5

(2018):

S56-65.

https://doi.org/10.4103/ijcm.IJCM_1

43_18. 